\title{
Intimate partner violence in Sri Lanka: a scoping review
}

\author{
S Guruge ${ }^{1}$, V Jayasuriya-Illesinghe ${ }^{1}$, N Gunawardena ${ }^{2}$, J Perera ${ }^{3}$
}

(Index words: intimate partner violence, scoping review, violence against women, Sri Lanka)

\begin{abstract}
South Asia is considered to have a high prevalence of intimate partner violence (IPV) against women. Therefore the World Health Organisation has called for contextspecific information about IPV from different regions. A scoping review of published and gray literature over the last 35 years was conducted using Arksey and O'Malley's framework. Reported prevalence of IPV in Sri Lanka ranged from $20-72 \%$, with recent reports of rates ranging from 25$35 \%$. Most research about IPV has been conducted in a few provinces and is based on the experience of legally married women. Individual, family, and societal risk factors for IPV have been studied, but their complex relationships have not been comprehensively investigated. Health consequences of IPV have been reported, with particular attention to physical health, but women are likely to underreport sexual violence. Women seek support mainly from informal networks, with only a few visiting agencies to obtain help. Little research has focused on health sector responses to IPV and their effectiveness. More research is needed on how to challenge gendered perceptions about IPV. Researchers should capture the experience of women in dating/cohabiting relationships and women in vulnerable sectors (post-conflict areas and rural areas), and assess how to effectively provide services to them. A critical evaluation of existing services and programms is also needed to advance evidence informed programme and policy changes in Sri Lanka.
\end{abstract}

Ceylon Medical Journal 2015; 60: 133-138

\section{Introduction}

Intimate partner violence (IPV) is defined as physical, sexual, and/or emotional abuse by a current or former marital or non-marital partner in the context of coercive control [1]. Most victims of IPV worldwide are women. The World Health Organisation recently reported that South-East Asia had a high prevalence of physical and sexual IPV among ever-partnered women worldwide
(37.7\%) [2]. A review of data from 81 countries revealed that South Asia has the second highest prevalence of IPV (41.7\%) [3]. Context specific information about IPV in South Asia is needed to understand these alarming prevalence rates, as well as to identify the determinants of IPV and how these factors generate the conditions under which women experience IPV in these settings.

Despite sharing many characteristics with other South Asian countries, Sri Lanka consistently ranks better in terms of maternal and child health, and life expectancy and educational attainment of women, yet available research suggests that the country has high rates of IPV [4-6]. Sri Lanka is currently transitioning from a low-to middle-income country and is emerging from a 25 -year-long civil war, so it is a unique context within which to examine the topic of IPV. In this article, we review literature about IPV in Sri Lanka to describe the prevalence, consequences and risk factors of IPV, and women's and health systems' responses to it.

\section{Methods}

A 'scoping' review is a technique used to 'map' relevant literature in a field of interest and is useful when the topic has not been comprehensively reviewed before. Scoping reviews help to summarise research findings by examining the extent, range and nature of the existing research. Unlike systematic reviews, scoping studies do not critically appraise the quality of the literature [7]. We used Arksey and O' Malley's five stage framework: developing a research question, identification of relevant literature, selecting a subset of literature for inclusion in the review, charting information from selected publications and summarising and presenting the results [7]. The broad research question that guided the review was: what is known from existing literature about IPV in Sri Lanka? We searched published and gray literature from 1980-2015 using different combinations of the following keywords: wife abuse/beating/ battering, domestic violence, intimate partner violence, spousal abuse, partner

\footnotetext{
${ }^{1}$ Daphne Cockwell School of Nursing, Ryerson University, Toronto, Canada, ${ }^{2}$ Department of Community Medicine, ${ }^{3}$ Faculty of Medicine, University of Colombo, Sri Lanka.
}

Correspondence: VJI, e-mail: <vathsalai@ryerson.ca>. Received 28 April and revised version accepted 23 May 2015. and reproduction in any medium, provided the original author and source are credited. 
abuse, gender-based violence and Sri Lanka. Sources of information included electronic bibliographic databases (such as MEDLINE, PsychINFO, CINAHL, Healthstar, EMBASE, Scopus), websites, peer reviewed journals, reference lists from articles and reports, repositories or archives at universities and libraries, as well as media reports, published and unpublished dissertations and theses, and conference proceedings. Studies were included if they focused on IPV against women by a male partner. Our initial search identified 271 articles, which were scanned using the following inclusion criteria: (1) focused on or included IPV against women; (2) focused on the Sri Lankan context; (3) written in English. Peer reviewed journal articles, conference presentations and published and unpublished dissertations and theses were included. After removing duplicates, narratives, expert opinions, and review articles, the number of articles included in the review was 39 .

Most of the studies were quantitative $(n=18 / 39)$ and mixed methods $(n=11 / 39)$ research. Some studies $(30 \%)$ were based on convenience samples of women $(n=31$ to 356) who were accessed and recruited from hospital clinics, medico-legal units, antenatal clinics, and other institutions [8-18]. Others (70\%) were community based studies ( $n=62$ to 2311 ) [19-44]. Sri Lanka was also one of the countries included in a multi country study on men and violence in Asia and the Pacific and in the GENACIS study (Gender, Alcohol and Culture: an International Study) [20]. These were the first studies on IPV in Sri Lanka to include men: the former was a large community based study including 1658 men and 653 women from four locations (Western, Central, Eastern, and North Central provinces); the latter was a qualitative study involving 7 men and 17 women. A few studies focused on children or adolescents who witnessed their mothers' experiences of IPV, and others studied IPV in the context of self-harm or as a consequence of the experiences of civil war [17, $30,34,35,38,39]$.

Most of these studies were conducted in the Western province $(n=15)$, followed Central $(n=8)$, Northern $(n=8)$, Eastern $(n=7)$, and North Western provinces $(n=5)$. Two studies included participants from more than one province $[18,32]$.

Figure 1 displays the number of studies on IPV over time, showing that research on the topic peaked after 2006 (i.e., beginning one year after the passage of the 2005 Domestic Violence Act of Sri Lanka and ending shortly after the cessation of the civil war in 2009).

\section{Results}

We reviewed the results of the 39 relevant studies on various aspects of IPV in Sri Lanka. The findings are presented in the following sections, which focus on the prevalence of IPV, health consequences of IPV, risk factors for IPV, women's responses to IPV, health system responses to IPV, and factors affecting women's careseeking behaviour, in Sri Lanka.

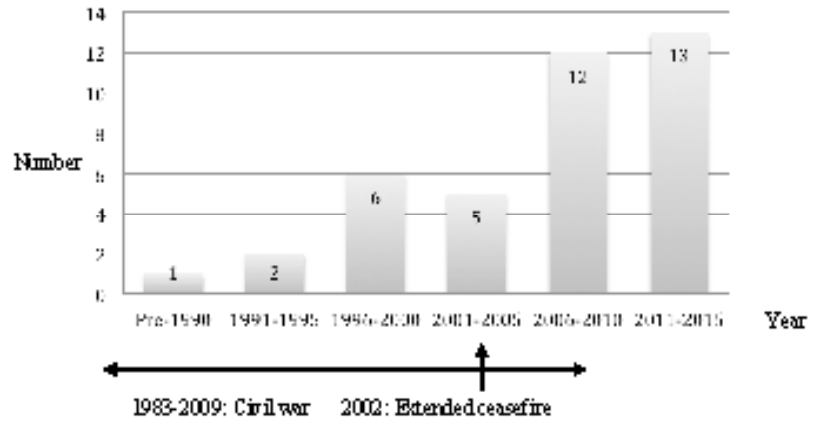

Figure 1. Number of studies over time.

IPV in Sri Lanka was first investigated by Saravanapavanthan in 1982 with a specific focus on 'wife abuse,' and this was followed by similar studies focusing on 'wife abuse,' 'wife battering,' and 'wife beating' [9, 15, 19, 27, $46,47]$. Since 2010 , research on IPV has included both marital and cohabiting relationships $[8,20,21,25,26$, 37]. We found only two studies that examined IPV in the context of dating relationships [37, 48].

Together, the literature suggests that $20-72 \%$ of women in different locations in Sri Lanka have experienced IPV. The highest prevalence rates were reported by women living on tea plantations in the Central Province $(72 \%)$ and in the urban poor areas of the Western Province (60\%) [21, 27]. As some of these prevalence rates are from studies conducted $10-15$ years ago, these findings are unlikely to reflect the current rates of IPV in Sri Lanka. Recent community based surveys reported that $24-34 \%$ of women in various regions of Sri Lanka experienced IPV $[25,26]$. The most recent survey conducted in 2013 , reported that $22 \%$ of women experienced IPV from a male partner, and $24 \%$ of male participants perpetrated IPV during their lifetime [20].

A number of studies $(n=15)$ were conducted in the Northern and Eastern Provinces, which were affected by the civil war from 1983-2009. Notably, several of these studies reported that IPV was more common than nonpartner violence against women even during the conflict period $[13,41]$. In addition to the civil war, the Indian Ocean tsunami of 2004 severely affected these provinces. Several studies focused on the post-tsunami context in these conflict affected areas, some did not document IPV from women's perspective [30, 34]. For example, one study interviewed non-government organisation (NGO) workers from this area, and another included children's accounts of parental conflict $[30,34]$. According to the study involving school children in an area affected by the tsunami in the Northern Province, $41 \%$ of children had witnessed violence directed against their mother by their father [34].

Experiences of IPV were documented for women in all stages of life, including adolescents, pregnant women, older adults and the types of IPV experienced included physical, sexual, emotional, and verbal abuse, and various 
controlling behaviour in varying frequencies [23, 27, 49]. However, the majority of studies predominantly reported physical violence. Overall, sexual abuse was one of the least reported forms of IPV in Sri Lanka, with rates ranging from 5 to $18 \%[20,25,26]$. The highest reported sexual violence rate $(20 \%)$ in Sri Lanka was based on men's self reports, and in the same study only $18 \%$ of women reported experiencing sexual abuse.

Physical health consequences of IPV in Sri Lanka have been documented, including head injuries, black eyes, contusions, abrasions, lacerations, and burns [10, 13$15,19,21,27,45,50]$. A number of studies were conducted in medico-legal settings, where physical injuries are more likely to be reported than other consequences of IPV. Only a few studies documented the psychological and mental health consequences of IPV: lowered selfesteem, suicidal ideation and suicide attempts [15, 23, $27,39]$. In one study, $12 \%$ of women reported IPV as the main reason for attempted suicide [17]. In another study, conducted in four provinces of Sri Lanka, 25\% of the women who had experienced IPV reported having suicidal thoughts, compared with $7 \%$ of women who had never experienced IPV [20]. Studies investigating IPV during pregnancy reported that $5-42 \%$ of women experienced IPV during pregnancy, resulting in pregnancy and labour complications and other adverse outcomes for themselves and their newborns [12, 47, 51]. These outcomes were reportedly 2-3 times higher among women who had experienced IPV during pregnancy compared with their counterparts $[12,20]$.

Studies identified a number of individual risk factors for IPV in Sri Lanka, including a woman's young age, low socioeconomic status and low educational attainment [9, 22-27, 44]. Abuser characteristics were also reported, including alcohol or drug abuse, unemployment, depression, and childhood experiences of violence [9, $13,19,20,22-27,44,48,51]$. Some relationship factors were reported as being associated with IPV, including suspicions of infidelity, sexual jealousy, extramarital relations, and marital disharmony [20, 21, 23, 25, 33, 48]. The role of these factors in increasing women's risk of IPV is not clear. For example, some studies identified alcohol abuse or community violence as risk factors for IPV, while others found that these factors are not consistently associated with IPV or only operate in combination with other factors such as low socioeconomic status [23, 27]. Several studies reported that risk factors for IPV in Sri Lanka, as in other patriarchal societies, are grounded in societal level risk factors such as 'traditional' gender roles and expectations [20, 29, 30, 32, 35, 37]. For example, one study found that up to $97 \%$ of men believed women should obey their husbands, and the majority of participants (both men and women) consider men to be the decision-makers in the family [20]. Another study found that obeying the husband was associated with a lower risk of IPV. Although dowry related violence appears to be less common in Sri Lanka compared with other South
Asian settings [4, 20, 25], Sri Lankan women, like their counterparts, are expected to wear conservative clothing in public places such as courts and other government institutions, occupy traditionally 'female' occupations, and face double standards in terms of sexual entitlement, sexual promiscuity, and pre- and extramarital sex [4, 13, 20, 25]. These risk factors are more significant for Sri Lankan women in certain regions and vary over time due to changing social and political situations. For example, IPV directed at women reportedly increased in the Northern and Eastern provinces after the end of the war [31].

The majority of the studies reported that Sri Lankan women, in general, do not disclose IPV to anyone and may continue to live in abusive relationships, in some cases for as long as 10 years [10, 13, 20, 23, 25, 33]. Those who sought help were more likely to approach family, neighbours, friends, and community leaders rather than formal services such as hospitals, police, or agencies providing services $[23,25,52,53]$. Several studies reported that most of the women who seek help from healthcare services do not disclose IPV $[13,15$, $23,25,45]$. The most recent survey of IPV in Sri Lanka conducted in 2013 found that only 32\% of women who sought healthcare for IPV-related health problems reported the abuse to their healthcare providers [20]. Nevertheless, the reporting rates in 2013 were higher than those reported in the past $[15,25]$. Few women made a complaint to the police or took legal action against the perpetrator $[15$, $52]$. One study reported that $13 \%$ of women who reported IPV made a complaint to the police and another reported that only a minority of complaints resulted in legal action against the abuser [20,52].

Research aimed at documenting the health system responses to IPV is limited in the Sri Lankan context. A few reports by NGOs document services provided by them such as legal aid, counselling, and shelters. According to these reports, during and after the period of civil war, and following the Indian Ocean tsunami, NGOs set up services in the regions most affected by these events and provided counselling services with the support of foreign funding agencies [4]. The first state supported health sector initiative for women experiencing IPV (the Gender-Based Violence (Desks) was implemented in 2002 [54]. The services, however, were primarily delivered by NGOs. Later, in 2007, a One Stop Crisis Center called 'Mithuru Piyasa' was set up in a government hospital, and similar centers have since been established in 20 government hospitals. The latter initiative, led by the Ministry of Health, provides for national level integration of IPV services. However, no studies have examined whether women access either type of centers, or whether the services meet their needs. Public Health Midwives (PHMs) in Sri Lanka have been trained to deliver a programme of education to recentlymarried couples which includes information about healthy relationships, family life and conflict resolution [4]. This 
health education programme is described as a pioneering IPV prevention programme, but, published literature about programme implementation and its effectiveness is not available [43].

Limited research has focused on perceptions and attitudes about IPV among healthcare providers. A study involving 30 nurses from public and private healthcare sectors in Sri Lanka revealed a range of personal and institutional barriers that affect how nurses care for women experiencing IPV [18]. Personal barriers included lack of knowledge and skills, and institutional barriers included lack of support from colleagues and other healthcare professionals, lack of communication and collaboration between professional groups, managers, and administrators, and lack of opportunities for developing relevant knowledge and skills. A study involving undergraduate male medical students revealed attitudinal barriers that could potentially affect IPV care provision; $33 \%$ of students surveyed believed wife beating was justified, $63 \%$ blamed women for instigating the violence, and $23 \%$ stated that occasional violence by a husband against his wife could help maintain the marriage [26]. A few studies involving women who sought services at healthcare institutions also reported stigmatizing attitudes toward women among health care providers, which discouraged the women from seeking services again $[4,23,25]$. A study describing the first-ever training programme for PHMs in 2009 study shows that their knowledge of IPV, perceived barriers to care provision, responsibility and confidence to identify and assist women experiencing IPV, improved 6 months after the training programme [26]. PHMs were more likely to identify, discuss and followup women experiencing IPV. Even though similar training is being provided to midwives in other areas of the country [4], more than 5 years since its inception, the effectiveness of this training has not been documented [4].

\section{Discussion}

Of the 20 million people in Sri Lanka, 55\% (10.5 million) are girls and women [55]. Available research indicates that IPV is a widespread problem in Sri Lanka affecting 1 in 3 women in the country. Based on the recent, most representative data, the overall prevalence of IPV in Sri Lanka is about $25-30 \%$, lower than estimates for other countries in South Asia. However, the prevalence rates of IPV in Sri Lanka must be considered with caution as they are primarily based on small studies, conceptualisation of IPV as occurring within the context of legal marriage, and only in a limited number of geographical locations. They also do not capture the heterogeneous nature of women in terms of their social, cultural, religious, economic, educational, and political backgrounds. Similarly, although IPV occurs in all forms of intimate relationships, and despite an increase in non-marital or co-habiting relationships, IPV in Sri Lanka continues to be conceptualised within the context of legal marriage. As a result, women in 'non-marital' intimate relationships are under represented in IPV research, so their experiences of IPV are poorly understood. Also, a general taboo on sexual matters and the lack of legal recognition of marital rape means that sexual violence and rape within marital relationships are largely overlooked. Also, the consequences of IPV for women in Sri Lanka have been primarily understood from a medico-legal perspective with a narrow focus on physical injuries.

The available studies suggest that individual and community level factors interact to make the situation worse for some women or some groups of women in Sri Lanka, but very little is known about the intersecting micro-, meso-, and macro-level factors in the Sri Lankan setting. As in many other countries, many of the factors that increase the risk for IPV in Sri Lanka are grounded in patriarchal relations and expectations prescribed for men and women, so the status of women relative to men in society in general, and within the context of marital relationships in particular, is of relevance [20,30]. Restrictive policies and practices increase Sri Lankan women's susceptibility to violence and tolerance of violence, while decreasing their ability to respond to IPV in a way that is most effective for them. For example, a recent government policy required women to seek permission from their husbands before leaving for foreign employment [57].

Overall, there appears to be an increase in the number of women who visit hospitals, the police and NGOs, to seek services, and more importantly to disclose IPV, than before. This signifies a positive change in the perception of IPV as no longer a private matter. However, little is known about the outcomes of such help-seeking behaviour, especially in the context of negative attitudes, as well as limited knowledge and skills, among health care professionals who provide services to women experiencing IPV [27, 42]. Additionally, IPV related services at government hospitals are largely dependent on NGOs to provide shelter, legal aid, and social services. Yet, there is a lack of recognition of the NGOs' role by the government. In the post-conflict context, the state perception of all NGO efforts as 'anti-government,' created barriers for these organizations to continue their work [57].

The Women's and Children's Desks in police stations and the Prevention of Domestic Violence Act provide some support for women seeking recourse from IPV. However, women face numerous obstacles when trying to obtain an Interim Protection Order (IPO). For example, they must produce evidence of violence, and delays in the issue of an IPO after a complaint is made place their lives at risk [58]. Moreover, even when a court rules against a perpetrator and issues an IPO, the ruling is often inefficacious because the perpetrator is not sufficiently monitored and continues to threaten or abuse the woman and her family and friends. In some cases, the abusers 
have threatened the (female) healthcare professionals who provide care to women experiencing IPV $[18,26]$.

Overall, there appears to be a positive change in the perception of IPV in Sri Lanka, which is no longer viewed as an entirely private matter, encouraging more women to seek outside services. However, in moving forward, there is a need to address many of the barriers that prevent women from seeking legal redress and recourse from IPV. These barriers include restrictive policies and practices that lower the status of women relative to men within the context of intimate relationships as well as their position in society.

\section{Funding} Canada.

International Development Research Center (IDRC),

\section{Acknowledgements}

We acknowledge the contribution made by Melanie Selvadurai (research assistant) in conducting online searches for this review.

\section{Conflicts of interests}

There are no conflicts of interest.

\section{References}

1. U.S. Department of Justice. Extent, Nature, and Consequences of Intimate Patner Violence: Findings From the National Violence Against Women Survey. Washington, US 2000 .

2. World Health Organization. Global and regional estimates of violence against women: prevalence and health effects of intimate partner violence and non-partner sexual violence. Geneva, Switzerland 2013.

3. Devries KM, Mak JYT, García-Moreno C, et al. Global Health. The Global Prevalence of Intimate Partner Violence Against Women. Science 2013; 340: 1527-28.

4. United Nations Population Fund. Health Sector Response to Gender-based Violence: An Assessment of the Asia Pacific Region. Bangkok, Thailand 2010.

5. Asian Development Bank. ADB Economics Working Paper Series: A Cross-Country Analysis of Achievements and Inequities in Economic Growth and Standards of Living. Metro Manila, Philippines 2009.

6. United Nations Development Programme. Sri Lanka Human Development Report 2012: Bridging Regional Disparities for Human Development. Sri Lanka 2012.

7. Arksey H, O'Malley L. Scoping studies towards a methodological framework: towards a methodological framework. Int J Soc Res Methodol 2005; 8: 19-32.

8. Kuruppaurachchi S. Status of School Library Development in Sri Lanka. SLLIM 2005; 1: 25-30.

9. Moonesinghe LN. The Prevalence and Correlation of Physical Abuse within Marriage in a Cohort of Pregnant

Vol. 60, No. 4, December 2015
Women in the Badulla District. Doctoral dissertation. University of Colombo. Colombo, Sri Lanka 2002.

10. Saravanapavanthan S. Wife beating: a study of sixty cases. Forensic Sci Int 1982; 29: 163-6.

11. Vidanapathirana M. Factors related to wife-battering; a medico-legal analysis. Galle Med J 2014; 19: 6-10.

12. Dinusha AK, Dissanayake SR, Dissanayake CG, Wickramasinghe VP. Patterns of abuse during pregnancy. Ceylon Med J 2006; 51: 1.

13. Centre for Women's Research. Women Victims of Violence: A Study on Admissions to a Provincial Gender Hospital. Colombo, Sri Lanka 1994.

14. Kodithuwakku KARI. Selected demographic and socioeconomic characteristics of the patients hospitalized following physical violence reporting to base hospital Matale. Doctoral dissertation. University of Colombo. Colombo, Sri Lanka 2002.

15. Vidanapathirana M. Factors related to wife-battering; a medico-legal analysis. Galle Med J 2014; 19: 6-10.

16. Kohombange CG. Intimate partner violence: the silent burden in Sri Lankan women. Inj Prev 2012; 18: 1.

17. Konradsen H, Hoek W, Peiris P. Reaching for the bottle of pesticide: a cry for help. Self-inflicted poisoning in Sri Lanka. Soc Sci Med 2006; 62: 1710-9.

18. Guruge S. Nurses' role in caring for women experiencing intimate partner violence in the Sri Lankan context. ISRN Nursing 2012; 1-8.

19. Nirthanan P. The Extent and Some Factors Associated with Wife Beating in the MOH Area Kantale. Doctoral dissertation. University of Colombo. Colombo, Sri Lanka 1999.

20. CARE International Sri Lanka. Broadening gender: why masculinities matter. Colombo, Sri Lanka 2013.

21. Deraniyagala S. An investigation into the incidence and causes of domestic violence in Colombo, Sri Lanka. WIN 1992.

22. Gomez S. A study on gender based violence in the Batticaloa district. Care International-Sri Lanka 2005; 1: 1-92.

23. International Center of Ethnic Studies. Sometimes There is No Blood: Domestic Violence and Rape in Rural Sri Lanka. Colombo, Sri Lanka 2000.

24. Jayasinghe S, Jayawardena P, Perera H. Influence of intimate partner violence on behaviour, psychological status and school performance of children in Sri Lanka. J Family Studies 2009; 15: 274-83.

25. Jayasuriya V, Wijewardena K, Axemo P. Intimate Partner Violence of women in the Capital province of Sri Lanka: prevalence, risk factors and help seeking. Violence Against Women 2011; 17: 1086-102.

26. Jayatilleke AC, Poudel KC, Sakisaka K, Yasuoka J, Jayatilleke AU, Jimba M. Wives' attitudes toward gender roles and their experience of intimate partner violence by husbands in Central province, Sri Lanka. J Interpers Violence 2011; 26: 414-32.

27. Centre for Women's Research. Report on Some Observations of the Incidence of Domestic Violence in 4 Locations in Sri Lanka and the Attitudes of the Women Towards the Violence. Colombo, Sri Lanka 2001. 
28. Somasundaram D, Sivayokan S. Rebuilding community resilience in a post-war context: developing insight and recommendations - a qualitative study in northern Sri Lanka. Int J Ment Health Syst 2013; 7: 1-25.

29. Haj-Yahia MM, Tishby O, de Zoysa P. Posttraumatic stress disorders among Sri Lankan university students as a consequence to their exposure to family violence. $J$ Interpers Violence 2009; 24: 2018-38.

30. Fisher S. Violence against women and natural disaster: findings from post-tsunami Sri Lanka. Violence Against Women 2010; 16: 902-18.

31. United Nations Security Council Resolutions. Women Count: Security Council Resolution 1325: Civil Society Monitoring. 2012.

32. Holmila M, Beccaria F, Ibanga A, et al. Gender, alcohol and intimate partner violence: qualitative comparative study. Drug-Educ Prev Polic 2014; 21: 398-407.

33. Jayatunge AAAVD. Women and Violence - A Case Study of Wendesiwatta Settlement. Thesis. University of Colombo. Colombo, Sri Lanka 1998.

34. Canti C, Schauer E, Neuner F. Beyond Individual War Trauma: Domestic Violence Against Children in Afghanistan and Sri Lanka. J Marital Fam Ther 2008; 34: 165-76.

35. Haj-Yahia MM, De Soyza P. Beliefs of Sri Lankan medical students about wife beating. J Interpers Violence 2007; 22: 22-49.

36. Center for Research on Women. A study of domestic violence in selected locations in Sri Lanka: Proceedings of Twelfth National Convention of Women's Studies. Colombo, Sri Lanka 2010.

37. Gunawardena N, Weerasinghe M, Rajapaksa L, Wijesekara P, Chathurangana PWP. Romance, sex and coercion: insights into undergraduate relationships. Sri Lanka J Psychiatry 2011; 2: 54-9.

38. Subramaniam J, Zulkarnain AH. Behavioural problems of children exposed to domestic violence in rural villages: a micro social work inquiry in Piranpattu village at Chankanai divisional secretariat, Jaffna, Sri Lanka. Procedia - Social Behavioural Science 2013; 91: 201-7.

39. Somasundaram D, Sivayokan S. Rebuilding community resilience in a post-war context: developing insight and recommendations - a qualitative study in northern Sri Lanka. Int J Ment Health Syst 2013; 7: 1-25.

40. Olupeliyawa AM, Ziad MH. Reporting of Domestic Violence Among Internationally Displaced Persons: a Sri Lankan Perspective. Proceedings of 40th Conference of Asia-Pacific Academic Consortium for Public Health, November 2008 Faculty of Medicine, University of Malaya, Kuala, Malaysia, 2004.

41. Kottegoda S, Samuel K, Emmanuel S. Reproductive Health Concerns in Six Conflict-affected areas of Sri Lanka. Reprod Health Matter 2008; 16: 75-82.

42. Wickramaratne V. Counselling needs of women in Sri Lanka. Proceedings of Seventh National Convention on Women's Studies Center for Women's Research Sri Lanka, 2000 .
43. Jayatilleke AC, Yoshikawa K, Yasuoka J, et al. Training Sri Lankan public health midwives on intimate partner violence: a pre- and post-intervention study. BMC Public Health 2015; 15: 331.

44. Phillips A. Gender ideologies and gender relations in the tea plantations. PALM Foundation 2000.

45. Subramanium P, Sivayogan S. The prevalence and pattern of wife beating in the Trincomalee district in Eastern Sri Lanka. South East Asian J Trop Med Public Health 2001; 32: 186-95.

46. De Silva H. Wife assault: a medical perspective. Sri Lankan Family Physician 1998; 17: 15-20.

47. Perera J, Abeynayake SD, Galabada DP. Gender based harassment among medical students. Proceedings of the 10th National Convention on Women's Studies, 2nd - 6th April, Sri Lanka, 2006.

48. Moonesinghe LN, Rajapakse LC, Samarasinghe G. Development of a screening instrument to detect physical abuse and its use in a cohort of pregnant women in Sri Lanka. Asia-Pac J Public Health 2004; 16: 138-44.

49. Nanayakkara RT. Analysis of Some Selected Aspects of Female Survivors of Intimate Partner Violence Reported to the Judicial Medical Officer, Colombo. Proceedings of Fifth Annual Academic Sessions, Faculty of Medicine Science, University of Sri Jayewardenepura, 2007.

50. Abeysena C. The Effect of Physical Activity and Physical Stress on Pregnancy Outcome. Doctoral dissertation. University of Colombo. Colombo, Sri Lanka, 2002.

51. Wijeratne PG. Father's alcohol consumption and family well being. Masters thesis. University of Colombo. Colombo, Sri Lanka, 1994.

52. International Center for Ethnic Studies. Domestic Violence Intervention Services in Sri Lanka: An Exploratory Mapping 2009-2011. Colombo, Sri Lanka, 2012.

53. Oxfam. Oxfam in Sri Lanka. Colombo, Sri Lanka, 2012.

54. Women in Need Sri Lanka. Police Counselling Desk. Women in Need, 2015. http://winsl.net/support-services/ police-counseling-desk (accessed on Mar 31, 2015)

55. Department of Census and Statistics - Sri Lanka. Population and Housing. Department of Census and Statistics - Sri Lanka.http://www.statistics.gov.lk/page.asp?page= Population\%20and\%20Housing (accessed on Apr 15, 2015).

56. Raday \& Crepeau. Office of the High Commissioner for Human rights. Geneva, Switzerland, 2014.

57. Herath D. Social Reconstruction amidst Material Reconstruction. Proceedings of Post-war reconstruction in Sri Lanka: Prospective and Challenges, International Center of Ethnic Studies (ICES), Kandy, Sri Lanka, 2010.

58. Policy Brief - Forum against Gender-base Violence. Implementing the national human rights action plan reducing violence against women. 2012. 